\title{
Vancomycin resistant enterococci gut Colonization and its associated factors among HIV infected patients on anti-Retro viral therapy in Ethiopia
}

Belayneh Regasa ( $\sim$ belayjanimen@gmail.com )

Arba Minch University

Zerihun Solomon

Arba Minch University

Mheret Tesfaye

Arba Minch University

\section{Research}

Keywords: Colonization, Gut, Human Immunodeficiency Virus, Vancomycin Resistant Enterococci

Posted Date: October 27th, 2020

DOI: https://doi.org/10.21203/rs.3.rs-96175/v1

License: (1) (i) This work is licensed under a Creative Commons Attribution 4.0 International License.

Read Full License 


\section{Abstract}

\section{Background}

The emergence of vancomycin resistant Enterococci (VRE) has alarmed the global infectious diseases community due to its tendency for colonization of the gastrointestinal tract. Human Immunodeficiency Virus (HIV) patients are colonized by vancomycin resistant Enterococci than other groups. The aim of this study was to determine the prevalence of vancomycin resistant Enterococci gut colonization and its associated factors among HIV infected patients on Anti-Retroviral Therapy (ART).

\section{Methods}

Institution based cross sectional study was conducted among HIV infected patients on ART at from June 1 to August 30, 2020. Socio-demographic and clinical data were collected by pre-tested structured questionnaire. Stool sample was collected and processed by standard microbiological techniques. Kirby Bauer Disc diffusion method was used to perform antimicrobial susceptibility testing. Data were entered by Epi data version 4.6.0.2 and analyzed by SPSS version 25 . P-value $\leq 0.05$ was considered as significant.

\section{Results}

Among a total of 200 study participants, colonization of Enterococci spp was isolated on $123(61.50 \%)$ respondents. Among these isolates, the prevalence of vancomycin resistant Enterococci colonization was 11.4\% [95\% Cl: (6.0-17.0)]. Enterococci isolates tested against commonly prescribed antibiotics showed highest rate of resistance to ampicillin (69.9\%). Multidrug resistances were observed in $49.59 \%$ of Enterococci isolates. Study participants who had prior antibiotic exposure for more than two weeks [AOR=7.35; 95\% Cl: (1.2144.64)] and hospitalization in the last six months [ AOR=5.68; 95\% Cl: (1.09 29.74)] were significantly associated with vancomycin resistant Enterococci gut colonization.

\section{Conclusion}

High prevalence of vancomycin resistant Enterococci gut colonization was found. Previous exposure to antibiotics for more than two weeks and previous hospitalization for more than six months were significant factors for vancomycin resistant Enterococci colonization. The isolated Enterococci had variable degrees of resistance to commonly prescribed antibiotics. Therefore, periodic surveillance on antimicrobial resistance pattern, adhering to rational use of antibiotics and implementing infection prevention protocols may reduce colonization by VRE.

\section{Background}


A major problem with the Enterococci is that they are very resistant to antibiotics and have ability to survive in harsh environments in community and persist in hospital settings (1). Because of this, they become important in health facility based settings (2). According to World Health Organization (WHO) report in 2017, vancomycin resistant Enterococci (VRE) is one of the most resistant bacteria in their "Global Priority list of antibiotic-resistant bacteria" (3). In the same manner, the Center for Disease Control and Prevention (CDC) has classified Enterococci among bacteria with a threat level of serious (4).

Currently, VRE are the cause of one-third and one fifth of all health care associated infections in the United States and in some European countries respectively (5). VRE are well known in causing different enterococcal infections such as infective endocarditis, bacteremia, urinary tract infection, intra-abdominal and pelvic infections, surgical wound infections, and very rarely Central nervous system (CNS) infection $(6,7)$. Many of these infections originate from intestinal flora of colonized individuals $(8)$.

Enterococci are enteric bacteria that are commonly recovered in feces collected from humans and from a variety of mammals as well as birds, reptiles and insects. The relative importance of Enterococcus as a pathogen has increased with the occurrence of high-level resistance to multiple antimicrobial drugs, such as ampicillin and vancomycin (9-13).

Vancomycin is the primary alternative drug to penicillin (plus an aminoglycoside) for treating enterococcal infections (13). It is active against most Gram positive bacteria and is considered as a drug of 'last resort'. However, nowadays Enterococcus spp that are resistant to vancomycin are emerged and spreading all over the world (12).

The term Vancomycin Resistant Enterococci (VRE) includes several combinations of enterococcal species including E. faecium (77\%) and E. faecalis (9\%), with the remaining $14 \%$ of isolates representing species rarely known in causing serious infections like $E$. gallinarum, $E$. casseliflavus, $E$. avium, and $E$. raffinosus $(10,14)$.

Vancomycin resistant Enterococci was first encountered in clinical isolates in England and France in 1986 as E. faecium, followed the next year by isolation of Vancomycin Resistant Enterococcus faecalis in the United States (15). They have become an important cause of serious invasive healthcare-associated infections globally $(6,7)$.

The emergence of VRE has alarmed the global infectious diseases community due to its tendency for colonization of the gastrointestinal (GI) tract and transfer of its resistance gene to Methicillin resistant Staphylococcus aureus (MRSA) to form a vancomycin-resistant Staphylococcus aureus (VRSA) isolate. Besides, VRE have different selection pressures for proliferation and rapid expansion of its resistant populations (16). Furthermore, few options are left for management of diseases caused by VRE, and hence causing increased mortality on infected individuals $(12,14)$. VRE now represent approximately one third of Enterococcus isolates (17). 
Asymptomatic VRE gut colonization precedes infection with susceptible hosts. Such susceptible hosts are patients who are exposed to multiple and prolonged courses of antimicrobial agents like Human Immunodeficiency virus (HIV) infected individuals, severely ill, hospitalized for long lengths of stay (LOS), living in a long-term care facility, located in close proximity to another colonized or infected patient, or hospitalized in a room previously occupied by a patient colonized with VRE $(2,18,19)$. Colonization is often obtained by vulnerable hosts in an environment with increased rate of patient colonization with VRE (20).

Vancomycin-resistant enterococci can persist in the environment for elongated periods ( $>1$ week), can contaminate almost any surface, and can be transferred from colonized or infected individual to another by health care workers $(9,13)$. Transmission of VRE can occur through direct contact with colonized or infected patients, indirect contact via the hands of healthcare workers, via contaminated personal protective equipment (PPE), environmental surfaces or from animals to human through food chain (21, 22). Usually colonization with VRE precedes infection, and the duration of colonization may be extremely extended ranging between 7 weeks and 3 years (22).

Colonization with VRE increases the risk of developing infection up to 5-10 folds (20). Whether VRE colonization leads to infection depends on the health status of the patient. Whereas immunocompetent patients colonized with VRE are at low risk for infection, weakened hosts such as HIV infected patients, patients with hematologic disorders, transplant recipients, or severely ill patients have an increased likelihood of developing infection following colonization $(19,20)$.

Compromised immune system of HIV infected patients increases the chances of acquiring various opportunistic infections (23). These individuals are at increased risk of developing infections, including infections caused by resistant bacteria pathogens (24). VRE is an important opportunistic bacterial pathogen causing significant morbidity and mortality in immunocompromised individuals like HIV patients $(8,25)$.

The prevalence of VRE was reported in Europe, Asia, Australia, South America and some African countries $(1,5,24,26)$. However, there is no sufficient data available on the prevalence and risk factors of VRE in developing countries like Ethiopia. Therefore, this study was conducted with the aim of determining the prevalence of vancomycin resistant enterococci gut colonization and its associated factors among HIV infected patients on Anti-Retroviral Therapy (ART).

\section{Methods}

\section{Study design, period and setting}

The study was conducted in Arba Minch General Hospital from June 1 to August 30, 2020. The hospital is located in Arba Minch town Gamo zone, $505 \mathrm{~km}$ South of Addis Ababa. The hospital has ART clinic where it provides different services for HIV-infected patients. The total population of Arba Minch town from 2007 central statistical agency (CSA) census report was 74,879, of whom 39,208 were men and 
35,671 women (27). The inclusion criteria is all HIV infected patients on ART at Arba Minch General Hospital, ART clinic during the study period. Exclusion criteria are those HIV infected patients who don't have Parent or guardian assent if they are $<18$ years old and those HIV infected patients who were critically ill and unable to respond.

\section{Sample size determination and sampling technique}

The required sample size was calculated for prevalence and associated factors. For prevalence, the sample size was determined by using single population proportion formula. The following assumption was considered with 7.8\% VRE prevalence from Gondar, Ethiopia (18), 95\% confidence level and marginal error which is half of the VRE prevalence $(7.8 \% / 2=3.9 \%)$ since VRE prevalence is less than $10 \%(28)$. However, when factors analysis was considered from previous studies such as previous antibiotic treatment for more than two weeks (51.7\%) (18) and (6.8\%) (2), level of hemoglobin (57.1\%) (16) and history of hospitalization (3.18\%) (2), we found a sample size of $48,54,44$ and 48 respectively; all of which are less than the sample size calculated by prevalence of VRE colonization. Therefore, sample size for the prevalence was taken after compensation for $10 \%$ non-response rate: $n=$ (sample size determined before addition of non-response rate * 0.1 ) + sample size determined before addition of non-response rate $=(182 * 0.1)+182=18+182=200$. Hence, the final sample size of this study was 200 .

\section{Sampling technique}

Systematic random sampling technique was used to select the study participants. Based on the 2020 three months (June-August, 2020) data obtained during COVID-19 pandemic from Arba Minch General Hospital ART clinic, $\mathrm{N}=366$ ( $\mathrm{N}=$ total number of study participants) HIV infected patients has visited the ART clinic. Assuming the same number of HIV- infected patients for the study period (June-August, 2020) and taking sample size of 200 , the $k^{\text {th }}$ value $(k=N / n=366 / 2002)$ is found to be 2 . The first one is selected with lottery method from 1 st and 2 nd patients and found to be 2 nd patient. Then every 2 nd patient was included.

Dependent variable was VRE gut colonization and independent variables were: Age, Sex, CD4 count, Level of hemoglobin, Previous antibiotic treatment for $>2$ weeks, Current visiting status (Inpatient or Outpatient), History of hospitalization in the last six months, Urinary catheterization, Co-morbid conditions (diabetes and renal failure).

\section{Data collection and laboratory processing}

A pretested well designed structured questionnaire was used to collect data from the study participants. The questionnaire was designed in English and translated in to Amharic language. The tool had two sections and was adapted by reviewing different literatures. The first section consisted of socio demographic questions and the second section embraced clinical data.

Upon the arrival of each study participant at ART clinic, written assent/consent was obtained. Sociodemographic and clinical data were collected by two nurses using a pretested well designed structured 
questionnaire through face-to-face interview. Moreover, recent CD4 count and hemoglobin level of respondents have been taken from ART clinic logbook.

\section{Isolation and Identification of Enterococci}

Each patient was instructed how to collect stool specimens, and informed to collect about $2 \mathrm{gm}$ of the faecal specimen in a sterile wide-mouth screw capped container labelled with the unique sample number, date, and time of collection. The collected stool specimens were transported to Arba Minch University College of Medicine and Health Sciences Microbiology and Parasitology laboratory.

Immediately after delivery, the transported stool specimens was streaked on Bile Esculin Azide agar (BEAA) (Park Scientific Limited, 24 Low Farm Place, Moulton Park, Northampton, NN3 6HY) and incubated for 24 hours at $37^{\circ} \mathrm{C}$. Plates were observed for appearance of characteristic growth with brown-black colored colonies in the medium and dark halo centers. Typical characteristic colonies were selected randomly for characterization and presumptive identification of Enterococciby Gram stains, Catalase test, Salt tolerance test and Heat tolerance test (29) (Fig. 2).

\section{Antimicrobial Susceptibility Testing}

The antimicrobial susceptibility testing was performed using Kirby Bauer disc diffusion method according to Clinical Laboratory Standards Institute guidelines (CLSI). After a pure colony was obtained, a loop full of bacteria were taken, transferred to a tube containing $5 \mathrm{ml}$ of sterile normal saline $(0.85 \%$ $\mathrm{NaCl})$ and mixed gently until it formed a homogenous suspension.

The turbidity of the suspension was determined by comparison with $0.5 \mathrm{McF}$ arland standards. A sterile swab was dipped into the suspension, and excess suspension was removed by pressing the swab against the wall of the tube. The entire surface of Muller Hinton Agar plate was uniformly flooded with suspensions and allowed to dry for about 3-5 minutes.

The antimicrobial impregnated disks were placed by using sterile forceps at least $24 \mathrm{~mm}$ away from each other to avoid the overlapping zone of inhibition. The disks were placed on agar plates and allowed to stand for 30 minutes to dissolve the antibiotics in the media (16). The plates were then inverted and incubated at $37^{\circ} \mathrm{C}$ for $16-24$ hours depending on the type of the antibiotic used and inhibition zone was measured using a ruler.

For instance, in the case of vancomycin the plates are inverted and incubated at $37^{\circ} \mathrm{c}$, and were held a full 24 hours for accurate detection of resistance. Zones were examined using transmitted light; the presence of a haze or any growth within the zone of inhibition indicates resistance for vancomycin. Grades of susceptibility pattern were recognized as sensitive, intermediate and resistant by comparison of zone of inhibition according to the 2018 CLSI guidelines (30). 
Antimicrobial susceptibility patterns of Enterococci were assessed against the following antibiotic discs: Penicillin (10 IU), Ampicillin (10 $\mu \mathrm{g})$, Tetracycline $(30 \mu \mathrm{g})$, Doxycycline $(30 \mu \mathrm{g})$, Ciprofloxacin $(5 \mu \mathrm{g})$, Vancomycin $(30 \mu \mathrm{g})$, Erythromycin $(15 \mu \mathrm{g})$ and Chloramphenicol $(30 \mu \mathrm{g})$, and were interpreted according to CLSI M100- 2018 (30). Antibiotics were selected based on CLSI recommendation, local availability (in health facility) and feasibility (cost and method of antimicrobial susceptibility test).

\section{Data Quality Assurance}

The reliability of the study findings were guaranteed through performing a pretest of $5 \%(n=10)$ on HIV infected individuals at Arba Minch Town Shecha Health Center, and implementing the standard quality measures through the entire process of data collection and laboratory work. Accordingly, one day training was given for data and sample collectors concerning on the research objective, data collection tools, sample collection procedures, and infection prevention protocols to be taken related with COVID-19 Pandemic.

The data were checked for completeness, accuracy, clarity, and consistency by the principal investigator on a daily basis. Standard Operating Procedures (SOP) for each procedure were strictly followed. It was verified that the media and reagents met expiration date and quality control parameters per CLSI guideline. All culture media were prepared following the manufacturer's instruction and sterility of the culture media was tested by incubating $5 \%$ of the batch at $35-37^{\circ} \mathrm{C}$ overnight for evaluation of possible contamination.

Moreover, E. faecalis ATCC 29212 and Staphylococcus aureus ATCC 25923 standard control strains obtained from Ethiopian Public Health Institution (EPHI) were used as a quality control for biochemical tests and agar plates including Mueller-Hinton agar with vancomycin disc to ensure testing performance of the potency of the disc as per CLSI 2018 guidelines (30).

\section{Statistical analysis}

Data were checked for its completeness, entered by Epi data version 4.6.0.2 software, and analyzed by SPSS version 25. Descriptive statistics like frequency, mean and percentage were used. The fitness of the model was checked by Hosmer-Lemeshow goodness of fit test.

Bivariable and multivariable logistic regression model was used to analyze the association between dependent and independent variables. Those variables with P-value $<0.25$ in bivariate analysis were considered as candidate for further multivariable analysis. P-values in the multivariable analysis, adjusted odds ratio (AOR) and 95\% confidence interval (Cl) were used to determine the strength of association. P-value $<0.05$ was considered as statistically significant. Finally, the study findings were explained in words, figures and tables.

\section{Results}


A total of 200 study participants were enrolled in this study. Among these the ratio of male to female was 1:1. The mean age and standard deviation was $38.68 \pm 10.97$ ranging from $18-67$ years. More than three fourth of the study participants 154 (77.0\%) came from urban settings (Table 1).

Table 1

Socio-Demographic characteristics of Study Participants Attending ART Clinic at Arba Minch General Hospital, Southern Ethiopia October $2020(\mathrm{~N}=200)$

\begin{tabular}{|lll|}
\hline Variables & Frequency & Percentage (\%) \\
\hline Sex & & \\
\hline Males & 100 & 50.0 \\
\hline Females & 100 & 50.0 \\
\hline Age & & \\
\hline$\leq 20$ & 12 & 6.0 \\
\hline $21-30$ & 30 & 15.0 \\
\hline $31-40$ & 78 & 39.0 \\
\hline $41-50$ & 47 & 23.5 \\
\hline$\geq 51$ & 33 & 16.5 \\
\hline Residence & & \\
\hline Rural & 46 & 23.0 \\
\hline Urban & 154 & 77.0 \\
\hline Educational Status & & \\
\hline Unable to read and write & 17 & 8.5 \\
\hline Able to read and write & 42 & 21.0 \\
\hline Primary (1-8) & 62 & 31.0 \\
\hline Secondary (9-12) & 62 & 31.0 \\
\hline College and above & 17 & 8.5 \\
\hline
\end{tabular}

\section{Clinical Characteristics of the Study Participants}

The clinical data showed that majority of the participants 187 (93.5\%) were outpatients and 168 (84.0\%) of the participants had CD 4 count $>350$. Less than half of the respondents 83 (41.5\%) had low hemoglobin level and $94(47.0 \%)$ had history of previous antibiotic use for $<2$ weeks. Majority of the study participants $174(87.0 \%)$ didn't have previous history of hospitalization in the last six months and 
180 (90.0\%) didn't have history of previous catheterization. Likewise, majority of the respondents 191 (95.5\%) and 193 (96.5\%) didn't have Diabetes Mellitus and Renal failure respectively (Table 2). 
Table 2

Clinical Characteristics of Study Participants Attending ART Clinic at Arba Minch General Hospital, Southern Ethiopia October $2020(\mathrm{~N}=200)$

\begin{tabular}{|c|c|c|}
\hline Visiting Status & Frequency & Percentage \\
\hline Outpatient & 187 & 93.5 \\
\hline Inpatient & 13 & 6.5 \\
\hline \multicolumn{3}{|l|}{ CD4 Count } \\
\hline$\leq 350$ & 32 & 16.0 \\
\hline$>350$ & 168 & 84.0 \\
\hline \multicolumn{3}{|c|}{ Hemoglobin Level } \\
\hline Low & 83 & 41.5 \\
\hline Normal & 111 & 55.5 \\
\hline High & 6 & 3.0 \\
\hline \multicolumn{3}{|c|}{ Previous Antibiotic Treatment } \\
\hline Never & 76 & 38.0 \\
\hline$\geq 2$ weeks & 30 & 15.0 \\
\hline$<2$ weeks & 94 & 47.0 \\
\hline \multicolumn{3}{|c|}{ History of hospitalization in the last six months } \\
\hline No & 174 & 87.0 \\
\hline Yes & 26 & 13.0 \\
\hline \multicolumn{3}{|c|}{ History of previous catheterization } \\
\hline No & 180 & 90.0 \\
\hline Yes & 20 & 10.0 \\
\hline \multicolumn{3}{|c|}{ Comorbid condition (Diabetes ) } \\
\hline No & 191 & 95.5 \\
\hline Yes & 9 & 4.5 \\
\hline \multicolumn{3}{|c|}{ Comorbid condition (Renal failure) } \\
\hline No & 193 & 96.5 \\
\hline Yes & 7 & 3.5 \\
\hline
\end{tabular}


Prevalence of Vancomycin Resistant Enterococcus Gut Colonization

From the total of 200 study participants, colonization of Enterococci species was seen on

123 (61.50\%) patients. Among these isolates, 14 (11.4\%) were vancomycin resistant (95\% Cl: $6.0-17.0 \%)$ (Fig. 1).

\section{Antimicrobial Resistance Profile of Isolated Enterococci}

Among 123 Enterococci isolates tested for commonly prescribed antimicrobial agents the highest rate of resistance was observed against ampicillin in which more than two thirds $86(69.9 \%)$ of the isolates were resistant (Fig. 2).

Multidrug resistances (MDR) were observed in slightly less than half 61 (49.59\%) of Enterococci isolates and less than one tenth $11(8.94 \%)$ of the isolates were resistant to all antimicrobials tested. All VRE isolates were MDR (Table 3).

Table 3

Profile of Multidrug Resistance Pattern of VRE isolates among clients Attending ART Clinic at Arba Minch General Hospital, Southern Ethiopia October $2020(n=14)$

\begin{tabular}{|lll|}
\hline Resistance rate & Combination of Antibiotics & No. (\%) of isolates tested \\
\hline R4 & G, P, TTC, MAC & $1(7.14)$ \\
\hline R5 & G, P, TTC, F, MAC & $2(14.28)$ \\
\hline R6 & G, P, TTC, F, MAC, PH & 11 (78.58) \\
\hline $\begin{array}{l}\text { Key; G-glycopeptides (vancomycin), P-penicillins (ampicillin and/or penicillin), TTC-tetracyclines } \\
\text { (tetracycline and/or doxycycline), MAC-macrolides (erythromycin), F-fluoroquinolones (ciprofloxacin), } \\
\begin{array}{l}\text { PH-phenicols (chloramphenicol), and R4-R6 Number of categories of antibiotics resistance from 4 to } \\
\text { 6, respectively }\end{array}\end{array}$ \\
\hline
\end{tabular}

\section{Factors Associated with Vancomycin Resistant Enterococcus Gut Colonization}

Factors independently associated with VRE gut colonization on bivariable analysis, and fit into a multivariable logistic regression model were sex, visiting status, history of catheterization, previous antibiotics treatment, history of hospitalization in the last six months and presence of Diabetes Mellitus (Tables 4 and 5). 
Table 4

Bivariable Logistic Regression Analysis on Factors Affecting Vancomycin Resistant Gut Colonization among clients Attending ART Clinic at Arba Minch General Hospital, Southern Ethiopia October 2020

\begin{tabular}{|c|c|c|c|c|c|}
\hline \multirow[t]{2}{*}{ Characteristics } & \multirow[t]{2}{*}{ Categories } & \multicolumn{2}{|c|}{ VRE gut colonization } & \multirow[t]{2}{*}{ COR } & \multirow{2}{*}{$\begin{array}{l}P \text { - } \\
\text { value }\end{array}$} \\
\hline & & $\begin{array}{l}\text { Yes, N } \\
(\%)\end{array}$ & No, N (\%) & & \\
\hline \multirow[t]{2}{*}{ Sex } & Females & $4(6.8)$ & $55(93.2)$ & 0.39 & $0.133^{*}$ \\
\hline & Males & $\begin{array}{l}10 \\
(15.6)\end{array}$ & $54(84.4)$ & 1 & \\
\hline \multirow[t]{2}{*}{ Residence } & Urban & $\begin{array}{l}11 \\
(11.6)\end{array}$ & $84(88.4)$ & 1.09 & 0.899 \\
\hline & Rural & $3(10.7)$ & $25(89.3)$ & 1 & \\
\hline \multirow[t]{2}{*}{ Visiting status } & Inpatient & $3(30.0)$ & $7(70.0)$ & 3.97 & $0.069 *$ \\
\hline & Outpatient & $11(9.7)$ & $\begin{array}{l}102 \\
(90.3)\end{array}$ & 1 & \\
\hline \multirow[t]{2}{*}{ CD4 count } & $\leq 350$ & $2(11.8)$ & $15(88.2)$ & 1.04 & 0.957 \\
\hline & $>350$ & $\begin{array}{l}12 \\
(11.3)\end{array}$ & $94(88.7)$ & 1 & \\
\hline \multirow[t]{3}{*}{ Previous Antibiotic Treatment } & Never & $2(4.9)$ & $39(95.1)$ & 1 & \\
\hline & $\geq 2$ weeks & $8(40.0)$ & $12(60.0)$ & 13.00 & $0.003^{*}$ \\
\hline & $<2$ weeks & $4(6.5)$ & $58(93.5)$ & 1.34 & 0.739 \\
\hline \multirow{2}{*}{$\begin{array}{l}\text { History of hospitalization in the last six } \\
\text { months }\end{array}$} & Yes & $6(37.5)$ & $10(62.5)$ & 7.43 & $0.002 *$ \\
\hline & No & $8(7.5)$ & $99(92.5)$ & 1 & \\
\hline \multirow[t]{2}{*}{ History of previous catheterization } & Yes & $4(25.0)$ & $12(75.0)$ & 3.23 & $0.078 *$ \\
\hline & No & $10(9.3)$ & $97(90.7)$ & 1 & \\
\hline \multirow[t]{2}{*}{ Diabetes Mellitus } & Yes & $2(28.6)$ & $5(71.4)$ & 3.48 & $0.163^{*}$ \\
\hline & No & $\begin{array}{l}12 \\
(10.3)\end{array}$ & $\begin{array}{l}104 \\
(89.7)\end{array}$ & 1 & \\
\hline
\end{tabular}


Table 5

Multivariable Logistic Regression Analysis on Factors Affecting Vancomycin Resistant Gut Colonization among clients Attending ART Clinic at Arba Minch General Hospital, Southern Ethiopia October 2020

\begin{tabular}{|c|c|c|c|c|c|}
\hline \multirow[t]{2}{*}{ Characteristics } & \multirow[t]{2}{*}{ Categories } & \multicolumn{2}{|c|}{ VRE isolates } & \multirow{2}{*}{$\begin{array}{l}\text { AOR } \\
(95 \% \mathrm{Cl})\end{array}$} & \multirow[t]{2}{*}{ P-value } \\
\hline & & Yes, $N(\%)$ & No, $\mathbf{N}(\%)$ & & \\
\hline \multirow[t]{2}{*}{ Sex } & Females & $4(6.8)$ & $55(93.2)$ & $\begin{array}{l}0.27 \\
(0.06- \\
1.25)\end{array}$ & 0.093 \\
\hline & Males & $10(15.6)$ & $54(84.4)$ & 1 & \\
\hline \multirow[t]{2}{*}{ Visiting status } & Inpatient & $3(30.0)$ & $7(70.0)$ & $\begin{array}{l}1.13 \\
(0.15- \\
8.43)\end{array}$ & 0.904 \\
\hline & Outpatient & $11(9.7)$ & $\begin{array}{l}102 \\
(90.3)\end{array}$ & 1 & \\
\hline \multirow[t]{3}{*}{ Previous Antibiotic Treatment } & Never & $2(4.9)$ & $39(95.1)$ & 1 & \\
\hline & $\geq 2$ weeks & $8(40.0)$ & $12(60.0)$ & $\begin{array}{l}7.35 \\
(1.21- \\
44.64)\end{array}$ & $0.030 * \star$ \\
\hline & $<2$ weeks & $4(6.5)$ & $58(93.5)$ & $\begin{array}{l}1.08 \\
(0.17- \\
6.80)\end{array}$ & 0.936 \\
\hline \multirow[t]{2}{*}{$\begin{array}{l}\text { History of hospitalization in the last } \\
\text { six months }\end{array}$} & Yes & $6(37.5)$ & $10(62.5)$ & $\begin{array}{l}5.68 \\
(1.09- \\
29.74)\end{array}$ & $0.040 * *$ \\
\hline & No & $8(7.5)$ & $99(92.5)$ & 1 & \\
\hline \multirow[t]{2}{*}{ History of previous catheterization } & Yes & $4(25.0)$ & $12(75.0)$ & $\begin{array}{l}1.38 \\
(0.27- \\
7.03)\end{array}$ & 0.701 \\
\hline & No & $10(9.3)$ & $97(90.7)$ & 1 & \\
\hline \multirow[t]{2}{*}{ Diabetes Mellitus } & Yes & $2(28.6)$ & $5(71.4)$ & $\begin{array}{l}1.81(0.21- \\
15.36)\end{array}$ & 0.588 \\
\hline & No & $12(10.3)$ & $\begin{array}{l}104 \\
(89.7)\end{array}$ & 1 & \\
\hline
\end{tabular}

\section{Discussion}

The hasty emergence and the increasing incidence of colonization with VRE have become challenging healthcare problems that have caused serious concern to health care providers and health authorities (2). In the present study, the prevalence of VRE among HIV infected patients was 11.4\% (95\% Cl: $6.0-17.0 \%$ ). 
This prevalence rate was consistent with other studies conducted in South Africa (14.5\%) (21), West Amhara, Ethiopia (7.7\%) (2), Addis Ababa, Ethiopia (6.7\%) (31) and Gondar, Northwest Ethiopia (7.8\%) (18).

However, the prevalence of VRE in our study was lower than the report from Ireland (44.1\%) (4), Germany (26.1\%) (32) Brazil (23.4\%) (1), India (19.6\%) (33), Saud Arabia (17.3\%) (5) and Iraq (46.4\%) (17). The lower prevalence in the present study might be due to the variation in study settings in which most of the previous countries have been using oral and intravenous vancomycin massively for human diseases (34, 35), and variation in study participants in which in the previous studies most of the study participants were hospitalized patients and critically ill patients in ICU who were frequently exposed to different antibiotics and experienced insertion of external devices like catheter (7).

On the other hand, this prevalence is higher than the report from USA (4.7\%) (36), Nigeria (4.07\%) (37) and Ethiopia (5.9\%) (16). The gradual increase in the prevalence of VRE might have contributed to this higher prevalence as supported by other studies $(32,38)$.

Enterococci isolates in our study showed various resistances to the tested antibiotics; namely, $69.9 \%$ to ampicillin, $54.5 \%$ to penicillin, $49.6 \%$ to erythromycin, $59.3 \%$ to tetracycline, $28.5 \%$ to ciprofloxacin and $21.1 \%$ to chloramphenicol. This finding is in line with studies conducted in India $64.9 \%$ (33) and Ethiopia $66.7 \%$ (39) for ampicillin; Ethiopia 64.9\% (40), 68\% (39) for tetracycline; and Brazil (45.7\%) (1) and Ethiopia $42.7 \%$ (9) (53.3\%) (31) for erythromycin.

However, the resistance profile in our study is lower than previous studies in India for tested antibiotics $75.9 \%$ for penicillin, $84.5 \%$ for tetracycline, $95.5 \%$ for ciprofloxacin, $92.1 \%$ for erythromycin and $42.3 \%$ for chloramphenicol (33); Uganda 69.4\% (15) and Ethiopia 77.3\% (41) for tetracycline; and Iraq (85.7\%) (17), Uganda (72\%) (15) and Ethiopia 63.2\% (41) erythromycin; This lower resistance pattern might be due to variation in study participants in which most of the participants in the previous studies were hospitalized patients who were taking different antibiotics that might be contributed for emergence of high rate of drug resistant microorganisms including Enterococci.

On the other hand, the antibiotic resistance profile in our study is higher as compared to studies conducted in Iran 41.2\% (42), Brazil 0\% (1), Uganda 1.4\% (15) and Ethiopia 36\% (41) for ampicillin; Brazil $32.6 \%$ (1) and Ethiopia 37.7\% (2) for tetracycline; and Brazil 10.9\% (1) for chloramphenicol. This discrepancy might be due to the fact that we are in the time of gradual increase in antibiotic resistance pattern which in turn might be due to overuse or misuse of antibiotics, inappropriate antibiotics prescription, extensive antibiotics use for agricultural purpose, mutation, gene transfer among bacteria, etc. (4).

Moreover, the present study also showed that $49.6 \%$ of Enterococci isolates were multidrug resistant. This result is lower than the findings in Iraq (85.7\%) (17) and Ethiopia $80.8 \%$ (41). In contrary, the result is higher than the finding in Ethiopia 29.5\% (16). The discrepancy of the result might be due to variation in 
geographical distribution of strain, trend and frequency of antibiotic prescription, community drug usage practice.

Regarding associated factors, the current study revealed that HIV patients who were exposed to antibiotics for more than two weeks previously were seven times more likely to be colonized with VRE as compared with HIV patients who never exposed to antibiotics previously [AOR $=7.35 ; 95 \% \mathrm{Cl}$ : (1.2144.64); $\mathrm{P}$ - value $=0.030]$. This result is in agreement with other studies conducted in Brazil (1), South Korea (43), Egypt (44), and Gondar and Ethiopia (2). The reason might be a prior exposure to antibiotics for a prolonged duration can cause VRE colonization due to the fact that the antibiotics exert selective pressure to Enterococci and alter the competing microbial flora in the GI tract allowing VRE to predominate as evidenced by other studies $(7,34)$.

Moreover, the present study also showed that HIV patients who had history of hospitalization in the last six months were six times more likely to be colonized with VRE as compared with HIV patients who didn't have history of hospitalization in the last six months [AOR $=5.68 ; 95 \% \mathrm{Cl}$ : $(1.09-29.74)$; P-value $=0.040$ ]. The finding is consistent with previous studies done in USA (36), South Korea (43) and Ethiopia (2). The reason might be VRE have been isolated from virtually every object within patient rooms since they are intrinsically resistant to several commonly used antibiotics in hospital and have ability to acquire resistance genes. Besides, they are ubiquitous in their presence and have high survivability on dry surfaces, thereby causing high VRE transmission rates within healthcare facilities $(7,9)$.

\section{Limitations Of The Study}

The isolated Enterococci were not identified to species level and no molecular characterization done due to resource limitation.

\section{Conclusions}

The prevalence of VRE gut colonization among HIV patients on ART was relatively high. Previous exposure to antibiotics for more than two weeks and previous hospitalization for more than six months were significant factors for vancomycin resistant enterococci gut colonization. The study also showed that the isolated Enterococci had variable degrees of resistance to commonly prescribed antibiotics.

Therefore periodic surveillance on antimicrobial resistance pattern of Enterococcus species is important for proper treatment, health professionals should strictly follow infection prevention protocols and further studies should be conducted on species identification and molecular characterization of Enterococci.

\section{Abbreviations}

ART: Anti-Retroviral Therapy AOR:Adjusted odd ratio BEAA:Bile Esculin Azide agar CDC:Center for Disease Control Cl:Confidence Interval CLSI:Clinical Laboratory Standards Institute guidelines CSA:Central statistical agency EPHI:Ethiopian Public Health Institution HAl:Hospital Acquired Infections HIV:Human 
Immunodeficiency Virus MDR:Multi Drug Resistant SOP:Standard Operating Procedures VRE:Vancomycin Resistance Enterococcus VRSA:Vancomycin-Resistant Staphylococcus aureus WHO:World Health Organization

\section{Declarations}

\section{Acknowledgments}

The authors would like to thank those who were involved in this research.

\section{Funding}

This research was supported by Arba Minch University. The funding agencies had no involvement in the design of the study, data collection and analysis, interpretation of data and writing the manuscript.

\section{Availability of data and materials}

The datasets generated and/or analyzed during the current study are not publicly available due to ethical and confidentiality reasons but are available from the corresponding author on reasonable request under the Ethics Committee's approval.

\section{Authors' contributions}

ZS, BRD, and MT carried out proposal development, data collection, data analysis and drafted the manuscript. All authors read and approved the final manuscript.

\section{Ethics approval and consent to participate}

Ethical clearance was obtained from Institutional Review Board (IRB) of Arba Minch University, College of Medicine and Health Sciences, and letter of permission to conduct the study was written to Arba Minch General Hospital. Official permission from Arba Minch General Hospital and an informed written assent/consent from each study participants (assent of those $<18$ age group from their family or guardian) were obtained.

All information that identifies study subjects were given code numbers and were kept confidential. The purpose of the study was clearly described to the study participants and the specimens collected from the patients were analyzed for the intended purpose only. For each confirmed resistant case, the responsible clinicians of the patient were informed for appropriate management.

\section{Consent for publication}

Not applicable.

\section{Competing interests}


The authors declare that they have no competing interests

\section{References}

1. Batistão DW, da F, Gontijo-Filho PP, Conceição N, Oliveira AG de, Ribas RM. Risk factors for vancomycin-resistant enterococci colonisation in critically ill patients. Mem Inst Oswaldo Cruz. 2012 Feb;107(1):57-63.

2. Agegne M, Abera B, Derbie A, Yismaw G, Shiferaw MB. Magnitude of Vancomycin-Resistant Enterococci (VRE) Colonization among HIV-Infected Patients Attending ART Clinic in West Amhara Government Hospitals. Int J Microbiol. 2018 Dec 31;2018:1-7.

3. Tacconelli E. Global Priority List of Antibiotic-Resistant Bacteria to Guide Research, Discovery, and Development of New Antibiotics. WHO. 2017.

4. Ventola CL. The Antibiotic Resistance Crisis: Part 1: Causes and Threats. Pharm Ther. 2015 Apr;40(4):277.

5. Alotaibi FE, Bukhari EE. Emergence of Vancomycin-resistant Enterococci at a Teaching Hospital, Saudi Arabia. Chin Med J (Engl). 2017 Feb;5(3):340-6. 130(.

6. Emaneini M, Hosseinkhani F, Jabalameli F, Nasiri MJ, Dadashi M, Pouriran R, et al. Prevalence of vancomycin-resistant Enterococcus in Iran: a systematic review and meta-analysis. Eur $\mathrm{J}$ Clin Microbiol Infect Dis. 2016 Sep;35(9):1387-92.

7. Alevizakos M, Gaitanidis A, Nasioudis D, Tori K, Flokas ME, Mylonakis E. Colonization With Vancomycin-Resistant Enterococci and Risk for Bloodstream Infection Among Patients With Malignancy: A Systematic Review and Meta-Analysis. Open Forum Infect Dis [Internet]. 2017 Jan 1 [cited 2019 Nov 5];4(1).

8. Susan L, Fraser CJD, Robert A, Salata. Vancomycin Resistant Enterococcal Infections: Background, Pathophysiology, Epidemiology. Medscape. 2018 Jun;97(4):223-7.

9. Murray PR, Rosenthal KS, Pfaller MA. Medical microbiology. 8th edition. Philadelphia, PA: Elsevier, 2016.

10. Nilsson 0 . Vancomycin resistant enterococci in farm animals - occurrence and importance. Infect Ecol Epidemiol. 2012 Jan;2(1):16959.

11. Sood S, Malhotra M, Das BK, Kapil A. Enterococcal infections \& antimicrobial resistance. Indian J Med Res. 2008;128(2):111-21.

12. Crank C, O’Driscoll T. Vancomycin-resistant enterococcal infections: epidemiology, clinical manifestations, and optimal management. Infect Drug Resist. 2015 Jul;217.

13. Carroll KC, Hobden JA, Miller S, Morse SA, Mietzner TA, Detrick B, et al. Jawetz, Melnick \& Adelberg's medical microbiology. 27 th edition. New York: Mcgraw-Hill Education; 2016.

14. Faron ML, Ledeboer NA, Buchan BW. Resistance Mechanisms, Epidemiology, and Approaches to Screening for Vancomycin-Resistant Enterococcus in the Health Care Setting. Kraft CS, editor. J Clin Microbiol. 2016 Oct;54(10):2436-47. 
15. Kateete DP, Edolu M, Kigozi E, Kisukye J, Baluku H, Mwiine FN, et al. Species, antibiotic susceptibility profiles and van gene frequencies among enterococci isolated from patients at Mulago National Referral Hospital in Kampala, Uganda. BMC Infect Dis. 2019 Dec;19(1):486.

16. Ali S, Alemayehu M, Dagnew M, Gebrecherkos T. Vancomycin-Resistant Enterococci and Its Associated Risk Factors among HIV-Positive and -Negative Clients Attending Dessie Referral Hospital, Northeast Ethiopia. Int J Microbiol. 2018 Jul;18;2018:1-9.

17. Al-Dahmoshi HOM, Rabeea HWS, Aridhee ASA, Al-Khafaji NSK, Al-Allak MH, Lazm AM, et al. Phenotypic Investigation of Vancomycin, Teicoplanin and Linezolid Resistance Among Enterococcus spp. Isolated from Children Diarrhea. J Pure Appl Microbiol. 2019 Mar;31(1):531-6. 13(.

18. Abebe W, Endris M, Tiruneh M, Moges F. Prevalence of vancomycin resistant Enterococci and associated risk factors among clients with and without HIV in Northwest Ethiopia: a cross-sectional study. BMC Public Health. 2014 Dec;14(1):185.

19. Amberpet R, Sistla S, Parija SC, Rameshkumar R. Risk factors for intestinal colonization with vancomycin resistant enterococci' A prospective study in a level III pediatric intensive care unit. J Lab Physicians. 2018 Mar;10(1):89-94.

20. Axelrad JE, Lebwohl B, Cuaresma E, Cadwell K, Green PHR, Freedberg DE. Gut colonization with vancomycin-resistant Enterococcus and risk for subsequent enteric infection. Gut Pathog. 2018 Jul;9(1):28. 10(.

21. Tatsing Foka FE, Kumar A, Ateba CN. Emergence of vancomycin-resistant enterococci in South Africa: Implications for public health. South Afr J Sci [Internet]. 2018 Sep 11 [cited 2019 Dec 3];114(9/10).

22. Orsi GB, Ciorba V. Vancomycin resistant enterococci healthcare associated infections. Ann Ig. 2013;25(10):485-92.

23. Rameshkumar MR, Arunagirinathan N. Drug-Resistant Bacterial Infections in HIV Patients. Intech Open. 2018 Dec;98(5).

24. Kwobah C, Ali I, Koskei P, Chumba D, Emonyi W, Mwangi A, et al. Antibiotic Sensitivity Patterns Among Postmortem Bacterial Isolates From HIV-Infected Patients in Western Kenya: A Crosssectional Descriptive Study. J Dis Glob Health. 2015 May;27:3:73-82.

25. Chinnambedu RS, Marimuthu RR, Sunil SS, Amrose P, Ramachandran V, Pachamuthu B. Changing antibiotic resistance profile of Staphylococcus aureus isolated from HIV patients (2012-2017) in Southern India. J Infect Public Health. 2020 Jan;1(1):75-9. 13(.

26. Remschmidt C, Schröder C, Behnke M, Gastmeier P, Geffers C, Kramer TS. Continuous increase of vancomycin resistance in enterococci causing nosocomial infections in Germany - 10 years of surveillance. Antimicrob Resist Infect Control. 2018 Apr;24(1):54. 7(.

27. Census. 2007 Tables: Southern Peoples, Nations and Nationalities Region Archived November 13, 2012, at the Way back Machine. Tables 2.1, and 3.4. 2007.

28. Naing L, Winn T, Rusli BN. Medical Statistics Practical Issues in Calculating the Sample Size for Prevalence Studies. Archives of Orofacial Sciences. 2006;1:9-14. 
29. Bile Esculin Azide. Agar ISO Formato 30 Plates [Internet]. [cited 2020 Jan 24].

30. Clinical and Laboratory Standards Institute. Performance Standards for Antimicrobial Susceptibility Testing, CLSI, Wayne, PA, USA, 28th edition, 2018.

31. Ferede ZT, Tullu KD, Derese SG, Yeshanew AG. Prevalence and antimicrobial susceptibility pattern of Enterococcus species isolated from different clinical samples at Black Lion Specialized Teaching Hospital, Addis Ababa, Ethiopia. BMC Res Notes.

32. Markwart R, Willrich N, Haller S, Noll I, Koppe U, Werner G, et al. The rise in vancomycin-resistant Enterococcus faecium in Germany: data from the German Antimicrobial Resistance Surveillance (ARS). Antimicrob Resist Infect Control. 2019 Dec;8(1):1-11.

33. Deshpande VR, Karmarkar MG, Mehta PR. Prevalence of multidrug-resistant enterococci in a tertiary care hospital in Mumbai, India. J Infect Dev Ctries. 2013 Feb;15(02):155-8. 7(.

34. Flokas ME, Karageorgos SA, Detsis M, Alevizakos M, Mylonakis E. Vancomycin-resistant enterococci colonisation, risk factors and risk for infection among hospitalised paediatric patients: a systematic review and meta-analysis. Int J Antimicrob Agents. 2017 May;49(5):565-72.

35. Cattoir V, Leclercq R. Twenty-five years of shared life with vancomycin-resistant enterococci: is it time to divorce? J Antimicrob Chemother. 2013 Apr;1(4):731-42. 68(.

36. Achenbach C, Flores E, Ferrell P, Pitrak D, Weber SG. Prevalence of and Risk Factors for Colonization With Vancomycin-Resistant Enterococcus Among Human Immunodeficiency Virus-Positive Outpatients. Infect Control Hosp Epidemiol. 2006 Jan;27(1):102-4.

37. Ekuma AE, Oduyebo OO, Efunshile AM, Konig B. Surveillance for vancomycin resistant enterococci in a tertiary institution in south western Nigeria. Afr J Infect Dis. 2016 Jan 1;10(2):121-6.

38. Swissnoso BN, Wassilew N, Rion V, Senn L, Gardiol C, et al. Emergence of vancomycin-resistant enterococci in Switzerland: a nation-wide survey. Antimicrob Resist Infect Control. 2019 Dec;8(1):16.

39. Yilema A, Moges F, Tadele S, Endris M, Kassu A, Abebe W, et al. Isolation of enterococci, their antimicrobial susceptibility patterns and associated factors among patients attending at the University of Gondar Teaching Hospital. BMC Infect Dis. 2017 Apr 17;17(1):276.

40. Abamecha A, Wondafrash B, Abdissa A. Antimicrobial resistance profile of Enterococcus species isolated from intestinal tracts of hospitalized patients in Jimma, Ethiopia. BMC Res Notes. 2015 Dec;8(1):213.

41. Toru M, Beyene G, Kassa T, Gizachew Z, Howe R, Yeshitila B. Prevalence and phenotypic characterization of Enterococcus species isolated from clinical samples of pediatric patients in Jimma University Specialized Hospital, south west Ethiopia. BMC Res Notes. 2018 Dec;11(1):281.

42. Anvarinejad M, Pouladfar G, Japoni A, Bolandparvaz S, Satiary Z, Mardaneh J. Diabetic Foot Infections: Antibiotic Susceptibility Patterns and Determination of Antibiotic Cross-Resistance in Clinical Isolates of Enterococcus Species During 2012-2014 in Shiraz, Iran. Arch Pediatr Infect Dis. 2016 Sep 6;5(2).

43. Kee SY, Park CW, Lee JE, Kwon YJ, Pyo HJ, Western Dialysis Physical Association, et al. Healthcareassociated risk factors of vancomycin-resistant Enterococci colonization among outpatients 
undergoing hemodialysis. Jpn J Infect Dis. 2012;65(1):57-60.

44. Moemen D, Tawfeek D, Badawy W. Healthcare-associated vancomycin resistant Enterococcus faecium infections in the Mansoura University Hospitals intensive care units, Egypt. Braz J Microbiol. 2015 Sep;46(3):777-83.

\section{Figures}

Figure 3 and 4 is not available in this version of the manuscript.

\section{Figures}

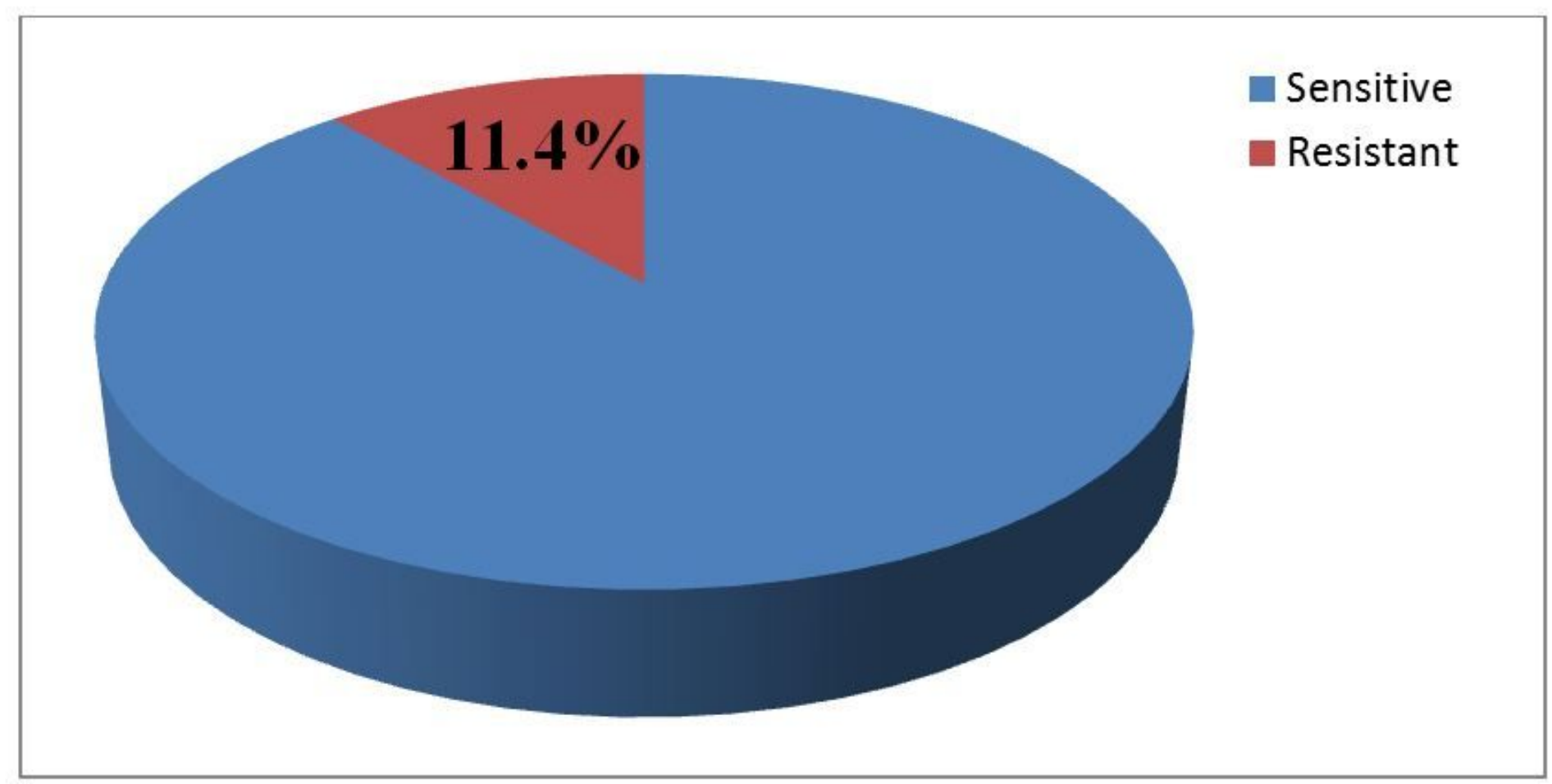

\section{Figure 1}

Prevalence of Vancomycin Resistant Enterococci Gut Colonization among HIV Infected Patients on ART at Arba Minch General Hospital, Southern Ethiopia, $2020(n=123)$ 


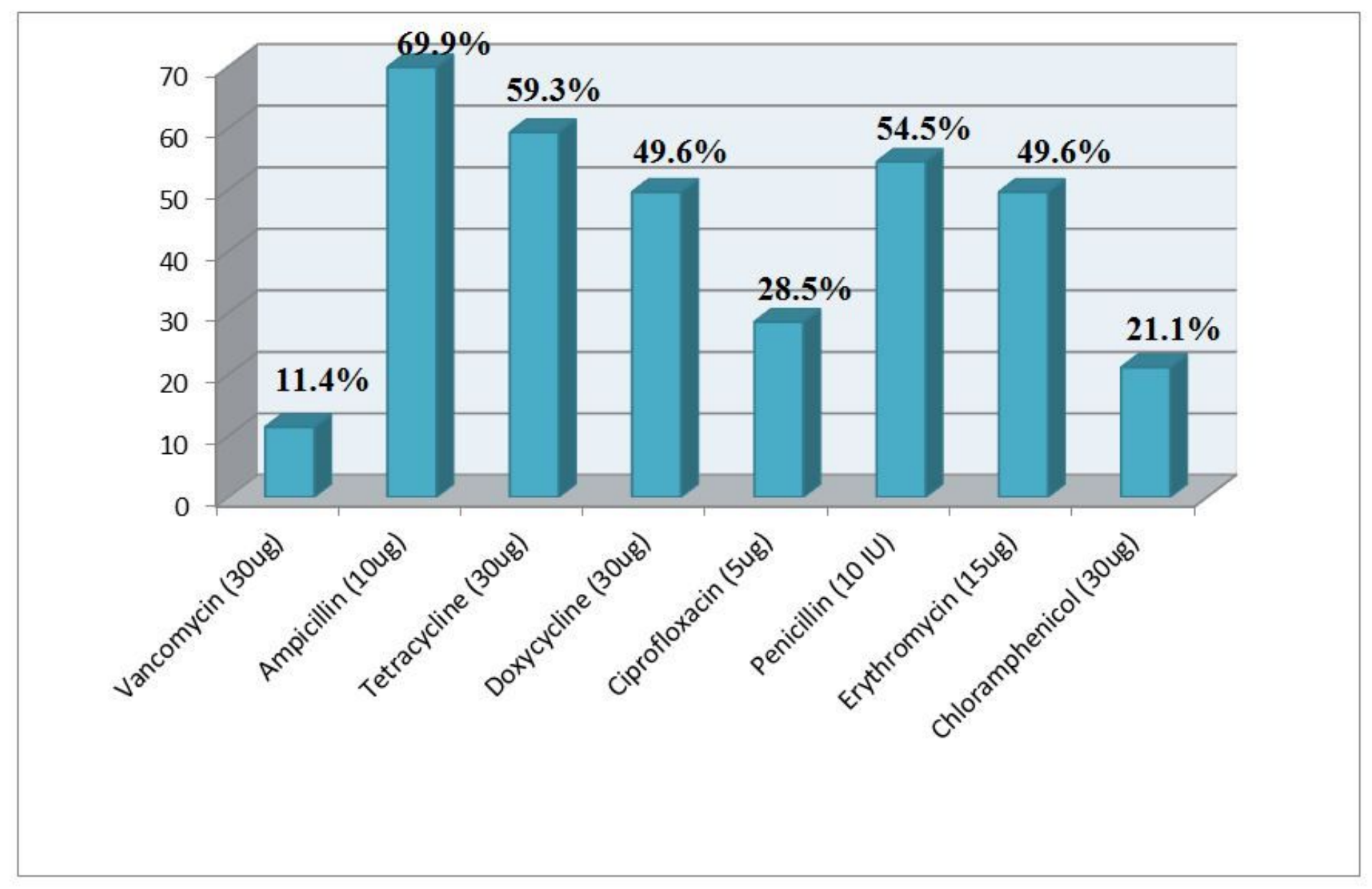

\section{Figure 2}

Antimicrobial Resistance Patterns of Isolated Enterococcus spp among HIV Infected Patients on ART at Arba Minch General Hospital, Southern Ethiopia, $2020(n=123)$

\section{Image not available with this version}

\section{Figure 3}

Zones of Inoculation for Stool Sample from HIV Infected Patients on ART at Arba Minch General Hospital, Southern Ethiopia, 2020 


\section{Image not available with this version}

Figure 4

Enterococcus spp on Bile Esculin Azide Agar Isolated from HIV Infected Patients on ART at Arba Minch General Hospital, Southern Ethiopia, 2020.

\section{Supplementary Files}

This is a list of supplementary files associated with this preprint. Click to download.

- Questionnaire.docx 